\title{
Sombras dos reis barbudos: a representação alegórica da realidade
}

\section{Gínia Maria Gomes*}

\begin{abstract}
Resumo: O ensaio faz uma leitura alegórica de Sombras dos reis barbudos, de José J. Veiga. Inicialmente procuramos analisar o ambiente repressivo da narrativa, cujo protagonista é um adolescente. A instalação da Companhia na cidade instaura um período de exceção, quando logo passa a vigorar um total controle sobre os habitantes, o que é feito por meio dos fiscais, que fazem acatar as proibições decretadas pela Companhia. A criação de muros é representativa da falta de liberdade, o que fica evidente quando a diversão passa a ser olhar os urubus que sobrevoam as casas. Na realidade, Veiga está falando alegoricamente do período pós-golpe militar de 1964, quando se instaura no país uma ditadura militar cujos mecanismos de repressão, como no romance, estão atentos àqueles que não compactuam com a ordem estabelecida.
\end{abstract}

\begin{abstract}
This essay carries out an allegorical reading of the text Sombras dos reis barbudos, by José J. Veiga. Initially we intended to review the repressive environment provided by the narrative, whose leading character is a teenager. The settlement of the Company in the city establishes a period of exception, when a total control over the inhabitants is implemented, which is made through the work of employees who must make people follow the prohibitions implemented by the Company. The creation of walls represents the lack of freedom, which is evident when people start finding amusement in watching the vultures that fly over their houses. Actually, Veiga is allegorically discussing the period right after the 1964 coup d'état, which was a time of military dictatorship in the country, whose mechanisms of repression, just like in this novel, are aware of and control those who do not comply with the established rules.
\end{abstract}

José J. Veiga estréia na literatura em 1959, com o livro Cavalinhos de Platiplanto, premiado no ano anterior. Já nesse livro de contos o autor recorre à alegoria para representar a realidade. Entre os vários contos que o compõem talvez "A usina atrás do morro" seja aquele que melhor represente o Brasil dos anos cinqüenta, em franco processo de industrialização, com suas máquinas impondo a modernidade de forma opressora e tornando opressiva a vida daqueles que ainda estavam em outro estágio cultural. Este conto já antecipa as duas novelas subseqüentes - A hora dos ruminantes e Sombras dos reis barbudos - escritas em plena ditadura. As três narrativas, contadas da perspectiva de um narrador-protagonista adolescente, têm como temática a instalação de uma fábrica, a qual, além de modificar os hábitos de uma

\footnotetext{
* Gínia Maria Gomes é professora de Literatura Brasileira na UFRGS. Organizou o livro de ensaios intitulado Euclides da Cunha: literatura e história, publicado pela Editora da Universidade/UFRGS, em 2005.
} 
comunidade, instaura um regime autoritário e de controle sobre os habitantes locais. No entanto, elas nada têm de panfletárias, ao contrário, a representação do real se faz no plano simbólico. É importante ressaltar que essa construção narrativa é uma posição consciente de Veiga, e está expressa em entrevista a Edla van Steen, quando afirma o seu compromisso como escritor: representar a política dando-lhe "uma dimensão mais profunda do que a simples condenação ou denúncia" (VEIGA, 1982, p. 81). Segundo o autor,cabe ao escritor discutir essas questões através dos símbolos.

É, pois essa presença de símbolos e metáforas que permite a leitura das narrativas de Veiga sob a perspectiva da alegoria, que, sendo uma"narrativa de caráter simbólico ou alusivo" (MORIER, 1961, p. 65), é portadora de um duplo sentido: "o imediato e literal do texto; e o outro, que constitui uma significação moral, psicológica ou teológica" (MORIER, 1961, p. 65). Essas construções imagéticas pontuam os textos de Veiga notadamente Sombras dos reis barbudos, objeto deste ensaio.

Na abertura da narrativa a situação de exceção é apresentada, sendo ela mesma a motivadora da escrita, já que, por sugestão da mãe, temerosa de ver o filho "andando por aî" (VEIGA, 1976, p. 1), o narrador-protagonista se propõe a relatar tudo o que aconteceu desde a chegada do tio, responsável pela fábrica que instaurou um novo tempo, tempo de opressão, que ainda é presente, embora não com a mesma intensidade do passado - "já que os fiscais já não fiscalizam com tanto rigor" (VEIGA, 1976, p. 1).

O narrador faz uma breve retrospectiva apresentando a ingerência do tio para instalar a Companhia. No período inicial o seu fundador era reverenciado: "Dar uma volta com tio Baltazar pela cidade era como andar na companhia de um deus ou de um santo, as pessoas só faltavam ajoelhar quando passávamos" (VEIGA, 1976, p. 15-16). O golpe (o termo é usado na narrativa), que depõe o tio, inaugura uma nova fase na cidade: de repressão, de autoritarismo, instaurado com a construção dos muros, "dividindo as ruas ao meio conforme o traçado, separando amigos, tapando vistas, escurecendo, abafando” (VEIGA, 1976, p. 27).

À construção dos muros, que impõem limites, cerceando a liberdade individual, surge a figura do fiscal, cujo papel é reprimir, fazendo valer as proibições da Companhia. O próprio pai do protagonista, sendo promovido a fiscal, imediatamente se investe de poder, o que é reforçado pela farda que passa a usar. O seu autoritarismo já se faz notar em casa com a esposa, que tem a incumbência de deixar a farda impecável: "se descobrisse nela uma ruga ou mancha meu pai não a vestia enquanto o defeito não fosse corrigido" (VEIGA, 1976, p. 27). Na cidade ele se impõe pelo temor: "como fiscal meu pai podia prejudicar ou beneficiar, os fiscais trabalhavam com carta branca e não podiam ser contestados" (VEIGA, 1976, p. 28). 
Está, pois, claramente expresso que a arbitrariedade e o despotismo caracteriza a atuação desses fiscais, que têm "carta branca" para disporem da vida dos cidadãos. Embora o protagonista não saiba o que o pai fiscalizava, ele o vê preenchendo fichas e as entregando na Companhia. Tudo indica que elas denunciavam aqueles que não se submetiam ao status quo. Isto se evidencia quando as mulheres, cujos maridos haviam sido presos, vão a sua casa clamar por justiça. A resposta do pai ao ser interpelado pelo filho não deixa dúvidas: “Querem que eu faça o impossível. Por que não aconselharam os maridos a andarem na linha? Agora agüentem" (VEIGA, 1976, p. 32).

A total falta de perspectiva imposta pelos muros, limitando o campo de visão e determinando o desconhecimento do que "acontecia na cidade" (VEIGA, 1976, p. 32), cria nos habitantes o hábito de olhar para cima, para os urubus que a sobrevoavam. Observá-los passa a ser a nova "mania" da comunidade. Para tal compram lunetas, binóculos e telescópios. Não tendo horizonte, olhar para o alto é a possibilidade de escapar de um cotidiano sufocante. No entanto, a nova diversão logo atrai a atenção do poder, e fica na iminência de ser arbitrariamente interrompida, o que o diálogo do protagonista com o pai deixa entrever: "- É que dentro de alguns dias não vai ter ninguém andando por aí de lunetinha e binoculinho na mão. Já estamos de olho neles” (VEIGA, 1976, p. 37). A proibição é tão insólitaque, quando advertidos pelo protagonista, seus amigos e colegas não lhe dão crédito. Lucas tem consciência de seu ato e das implicações em relação ao pai, pois "eles agora estavam com a mania de fazer inquérito para tudo" (VEIGA, 1976, p. 40). Tal proibição demonstra que qualquer liberdade deve ser cerceada, nada pode fugir ao controle da Companhia, mesmo que seja um simples divertimento.

Os urubus, que antes estavam sobrevoando a cidade, acabam por descer e penetrar nas casas, passando a conviver com os seus habitantes. É uma total inversão de valores. Parece que a situação é tão caótica que "estes bichos antes tão mal-quistos" (VEIGA, 1976, p. 45) transformam-se em lenitivo de uma vida sem perspectiva. É neste momento, quando a população está voltada para os urubus, que novas proibições têm lugar - algumas delas "inteiramente bobocas" (VEIGA, 1976, p. 46). Outras, consideradas irritantes, são comentadas pelo narrador, como a de "cortar caminho" (VEIGA, 1976, p. 46) pulando o muro, o que restringia ainda mais o trânsito das pessoas: elas deviam se conformar com o percurso traçado pela Companhia. Aqueles que infringiam esta regra tinham o corpo mutilado: dedos costurados, "aparelho de ferro atarrachado nas pernas para impedi-las de se dobrarem" (VEIGA, 1976, p. 47), etc. 
Também a proibição de "rir em público" (VEIGA, 1976, p. 47) é objeto de comentário e está relacionada aos fiscais que eram objeto de riso quando da tentativa de prender os urubus. Os meninos logo encontraram um meio de não serem flagrados como infratores: ou procuravam não olhar ou colocavam na boca“uma pelota de pano ou algodão" (VEIGA, 1976, p. 47).

Outra providência inusitada foi contra os urubus que não poderiam ficar na rua. Deveriam ser registrados e identificados com uma chapinha. Um indício a mais de que nada poderia fugir ao controle da Companhia.

Este controle fica ainda mais evidente quando o pai do protagonista resolve largar a fábrica e abrir o seu próprio negócio. Enfrenta uma série de obstáculos e não consegue sobreviver às dificuldades que lhe são impostas. Embora nem todos os empecilhos estejam diretamente vinculados à Companhia, a maioria deles parece ter sido de sua responsabilidade. Primeiro é o caieiro que não cumpre com o prazo. Depois é o carpinteiro, cujo trabalho já havia sido contratado, que pretexta ter iniciado "um serviço grande para a Companhia, que ele foi obrigado a pegar para não ficar parado e agora tão cedo ele não podia pensar em outro compromisso" (VEIGA, 1976, p. 103). Aqui fica evidente a ingerência da Companhia, pois não apenas este carpinteiro não está disponível, mas nenhum dos outros se dispõe a fazer as prateleiras, alegando sobrecarga de trabalho: "De repente todos ficaram muito ocupados, parecendo que a cidade inteira tinha entrado numa febre de encomendar serviço de carpintaria" (VEIGA, 1976, p. 105). O fato de nenhum deles realizar o serviço pode ser visto como controle da Companhia. Assim como todos deviam transitar pelos caminhos impostos pelos muros, a ninguém era dado o direito de seguir um caminho próprio, que não fora determinado pelos detentores do poder. O cerco se fecha quando o pai tenta comprar madeira. Percorre depósitos e fornecedores os quais pretextam que não a tem "nem para remédio", porque "todo o estoque tinha sido requisitado pela Companhia, para que fim não sabíamos" (VEIGA, 1976, p. 106). Mesmo diante de todos esses percalços o pai ainda assim não desiste. Vai comprar a madeira na cidade vizinha. A carga é apreendida e ele "denunciado como contrabandista" (VEIGA, 1976, p. 106). Finalmente flagrado em um ato ilegal é processado e aprisionado. Vítima de algum fiscal zeloso no cumprimento de suas tarefas, não tem alternativa e sucumbe "a arbitrariedade do poder, de cujas malhas não consegue escapar, o que suas palavras traduzem: “- Eu fiz o que pude por você e por Lu, mas eles puderam mais" (VEIGA, 1976, p. 107). Na realidade, as suas próprias palavras diante das mulheres dos prisioneiros identificam a situação que está vivendo; assim também ele não andou na linha. 
O aprisionamento do pai não significa o termo das proibições ditadas pela Companhia que, a cada dia, impõe novas restrições, trazendo mais sofrimento à população que, no entanto, consegue se adaptar e criar subterfúgios para não sucumbir: "Todo mundo vem dizendo há muito tempo que a vida está insuportável, e que se continuar assim... Pois continua, e cada dia piora, e estamos aí agüentando. Quando parece que não vamos agüentar mais e cair no desespero, alguém inventa um passatempo para nos distrair." (VEIGA, 1976, p. 116)

O último passatempo apresentado é o vôo dos homens. Quando aparecem os primeiros homens-pássaros o sentimento dos habitantes é de temor, pois poderia ser "uma nova manobra da Companhia" (VEIGA, 1976, p. 123); depois, ao perceberem que também ela está atemorizada, têm um novo alento, porque "se a novidade era ruim para a Companhia, tinha que ser boa para nós" (VEIGA, 1976, p. 132). Então, o espetáculo dos homens-pássaros passa a ser apreciado "verdadeiramente" (VEIGA, 1976, p. 132).

É interessante observar o simbolismo do vôo:

Nos mitos (Ícaro) e nos sonhos, o vôo exprime um desejo de sublimação, de busca de uma harmonia interior, de uma ultrapassagem dos conflitos. Esse sonho é particularmente comum entre as pessoas nervosas, pouco capazes de realizar por si próprias o seu desejo de elevar-se. Simbolicamente, significa: não poder voar. (CHEVALIER; GHEERBRANT, 1990. p. 964 )

Embora Chevalier e Gheerbrant se concentrem no mito e no sonho, pode-se perceber alguns aspectos que estão em sintonia com o vôo das personagens de Veiga. Impotentes para resolverem seus conflitos, sufocadas em um ambiente opressivo, só lhes resta voar, ultrapassando os limites de um mundo cercado por muros. Também essa tentativa de romper ao cerceamento é submetida à proibição; agora eles não podiam "olhar para cima sob qualquer pretexto" (VEIGA, 1976, p. 132). Mais uma vez tiveram que se submeter, pois tinham consciência de que "a Companhia tinha se aparelhado em todos os sentidos, e nós compreendemos que ela não estava brincando" (VEIGA, 1976, p. 132). Apesar de o vôo, em Sombras dos reis barbudos, não aparecer como sonho, o narrador apresenta a avaliação de um homem que encontrara na loja de Seu Chamun: esta aponta para a possibilidade de uma “alucinação coletiva" (VEIGA, 1976, p.135), considerada um remédio contra a loucura, decorrente do desejo de voar, de libertar-se deste mundo opressivo.

A leitura de Sombras do reis barbudos (e da obra de José J. Veiga como um todo) permite a afirmação de que o autor está falando alegoricamente do momento histórico-social que o País viveu a partir de 1964, com o golpe militar. Período autoritário, repressivo, o que fica evidente ao lembrarmos, por exemplo, do AI5, através do qual os mecanismos de 
repressão se fortaleceram. Veiga cumpre sua proposta de representar a realidade sob uma “dimensão mais profunda". O contexto social arbitrário do romance certamente é uma leitura alegórica do País, no qual a repressão vigorou até quase o final da década de 70 . Se no romance os homens começaram a voar sobre a cidade, no País muitos voaram para outros lugares em busca de ares menos opressivos e de uma vida em que pudessem exercer a tão sonhada liberdade.

\section{Referências}

CHEVALIER, Jean, GHEERBRANT, Alain. Dicionário de símbolos. Rio de Janeiro: José Olympio, 1990. p. 964.

MORIER, Henri. Dictionnaire de poètique et de rhétorique. Paris: PUF, 1941. p. 65-84.

VEIGA, José J. Sombras dos reis barbudos. Rio de Janeiro: Civilização Brasileira, 1976. 